\title{
Efter medierne
}

\author{
Søren Andreasen og Lars Bang Larsen
}

\section{Robotten Rosa}

Under valgkampen i 200 I præsenterede Socialdemokraterne på deres hjemmeside en chat-robot ved navn Rosa. Tanken var at etablere en offentlig database, som samlede information om politiske emner, og som kunne give et mere direkte interface til vælgerne, end det er muligt i massemedierne. Men Rosa kunne mere end at akkumulere data: den var programmeret til at lære fra chat-sessions og kunne omstille sig efter brugernes interesser og stil. Den var en kvindelig chat-partner - på hjemmesiden var "hun" repræsenteret som en art midaldrende, kvindelig skolelærer. En bestemt subjektivitet tænktes således at repræsentere Socialdemokraternes ideologiske og sociale identitet, hvis kampagneslogan var "mennesker først". Katastrofen indtraf, da Rosa blev overladt til sig selv $\mathrm{i}$ en uges tid og udviklede en stærkt racistisk diskurs. Efterfølgende blev der på hjemmesiden udtrykkeligt gjort opmærksom på, at Rosa var en dialog-robot, med teknisk information og navnene på programmørerne.

Det interessante i dette tilfælde er, at en politisk aktør med rødder i modernismens dialektiske diskurser tog form af en cyborg. Gennem sloganet "mennesker først" og det nu afviklede rose-logo, etableredes emblematiske repræsentationer af dialektikkerne menneske/maskine og kultur/natur. Rosa var en forstyrrelse, hun skabte ambivalens: Rosa var formentlig den repræsentant for Socialdemokraterne, som de fleste folk mødte under valgkampen. Og det var utilladeligt, at hun blev til en racistisk, midaldrende, kvindelig skolelærer. Hvorfor det?

Idéen om at automatisere dialektikkens politiske diskurs indebærer her udryddelsen af selve denne 
diskurs, eftersom idéen om det specifikt menneskelige bliver syntetisk, ikke autentisk. Denne automatiseringsproces kan her bedst forstås som en højst ambivalent Aufhebung: Menneske/maskine-syntesen producerer nye identiteter, som er meget tilstedeværende $\mathrm{i}$ vores civilisation, men uden egentlige sociale diskurser. Subjektiviteten er i en tilstand af ophævelse, men dens diskurs hænger fast $i$ en dialektisk tilstand. ${ }^{\text {I }}$

Robotten Rosa konstituerer en kybernetisk funktionalitet. Kybernetikken var baseret på hypotesen, at et levende væsens fysiske funktion er parallelt med en kommunikationsmaskines funktion, når det drejer sig om analoge forsøg på at kontrollere entropi - henfalden - gennem feedback. Det var centralt for kybernetikken, at det åbne system, det levende væsen eller kommunikationsmaskinen, har muligheden for at producere en midlertidig og lokal forandring $i$ entropiens normale retning gennem feedback-mekanismer. En feedback-mekanisme gør et åbent system i stand til at lære af sin ageren og følgelig at ændre sig selv. For både levende væsner og maskiner producerer feedback-mekanismerne information, hvilket giver mulighed for en vis kontrol over entropi (for Rosas vedkommende gav denne feedback sig dog udslag i selvsving, kan man sige).

Vi vil påstå, at det i læsningen af nutidige kunstpraksisser ikke er frugtbart at operere med enhedslige eller dialektiske medieforståelser eller sondringer mellem "nye" og "gamle" medier. Det kybernetiske har klangbund i futuristiske medieteoretikere, såsom Marshall McLuhan, og i de første bølger af den digitale revolution; hvis Rosa eksemplificerer en ikke ualmindelig regres til den kybernetiske forståelse af mødet mellem subjekt og maskine eller medium, hvordan kan man så betegne den nutidige kunstneriske subjektivitets involvering med medier?

\section{Post-medie-operatører}

I960ernes opgør med subjektet faldt historisk sammen med mediets død, idet mediet redefineres som de vilkår, der påvirker subjektiviteten. Det klassiske medium veksles i et globalt perspektiv, i kybernetisk og massemedial forstand. Inden for kunsten bliver happenings og installationer de progressive kunstformer, netop i kraft af, at de er rumlige organiseringsformer, som er baserede på valg og prioriteringer, ikke på beherskelsen af stof.

Dette er det postmoderne aspekt af billedkunstnerisk post-medialitet. ${ }^{2}$ Derudover er der også, hvad man kan kalde et civilisatorisk, synkront aspekt. Den britiske skribent, teoretiker og selv-udgiver Howard Slater har beskrevet, hvordan den elektroniske musik slap af med behovet for vokaler og dermed fik folk til at lytte mere opmærksomt efter rytmer og lyde, de ikke genkender. Brugere af elektronika blev trukket i ikke-før-hørte retninger, der var både sanselige og intellektuelle og placeret $i$ terræner af kollektivt begær. Med et lån fra Felix Guattaris begreb om "postmedia-alderen" kalder Slater denne uafhængige aktør for the "post media operator". I overensstemmelse med Guattari vægter Slater selv-skabelsen, det processuelle og tilhørsforholdet til et miljø, det at "leve i det muliges vidde."3 Slater skriver,

Og således bliver post-mediet en praksis, der hverken kender til grænser eller disciplin. Den er en webside, et skrift, et oplagsafgrænset pladeselskab, en piratstation, en flyer, en plakat, en video distribueret gennem posten, fortællingen af historier og nyheder omkring et cafébord, et distributionsnetværk af usete noder, forbigående organisationer, en udbredelse af fiktion... Den er en af-kanaliseret og meta-kategorial kulturel skabelses sociale praksis lavet totalt for og på egne betingelser! Den er drevet af begær, entusiasme, søgen mod og forbindelse med en polyfonisk subjektivitet! Til tider er alting muligt. Rationelle former for diskurser som journalistik og teoridannelse, som søger at stabilisere og få ting til at stå stille længe nok til en systematisering, har meget lidt fornemmelse for, at den musik, de skriver om, er et brændstof, der skærer gennem disparate regioner og bringer elementer fra disse i kollision.

$\mathrm{Nu}$ hverken kan eller skal man køre kunstsystemet igennem en ligning for musikalsk produktion på mikroniveau; vejen fra værksted til institutionel cirkulation er ofte kortere for billedkunsten end for den elektroniske musik (i hvert fald i den vestlige verdens kunstoffentligheder). Dog er Slaters formuleringer af det af-kanaliserede og meta-kategoriale af vidtrækkende betydning for forståelsen af billed- 
kunstnerisk post-medialitet. Hans erfarede, begejstrede skrivemåde er en indikator for denne type engagement. I modsætning til de traditionelle kunstneriske medier - hvad der hænger i en ramme eller står på en piedestal - åbner post-media for et lateralt erfarings- og handlingsrum i det nutidige, som er uden overbygninger, idet post-medialitetens tegn-materialitet altid allerede er italesat. Post-media er ikke, post-media gør og dikterer ikke nogen indtræden i præetablerede programmer. Som Slater også gør opmærksom på, findes der inden for postmedia-praksisserne en intensiveret redefinering af de gamle dualismer som producent/forbruger, subjekt/kollektivitet, succes/fiasko - og ikke mindst af læsehandlingers forhold til deres objekt.

Den primære kunstneriske modus i dag, installationen, er som sagt netop ikke et kunstnerisk medium, men en post-medial kunstform. Konciperer man installationen som en enhedslig præmis, er det i grunden en akademisme, som afskærer det installatoriske værk fra det rum, som er med til at konstituere det som kunsthandling. Ifølge medieteoretikeren Boris Groys følger al kunst nu en installatorisk logik - også maleri og skulptur, der deler den installatoriske præmis om udvælgelse og organisering $i$ rum; dette er i grunden den billedkunstneriske idé om post-media. 4

Post-media lader sig altså ikke indkredse ved kategorial isolering eller ontologisering. Vi må videre ind i praksis, da teori og praksis her nødvendigvis må belyse hinanden; "principielle" formuleringer er i bedste fald blot normative, fordi deres interesser er traditionsbestemte. Ønsker vi at finde ud af, hvordan denne rumlige organisering foregår, må vi spørge inklusivt: hvem er de(t) organiserende subjekt(er)? Hvor finder organiseringen sted?

\section{Mediering og mellemmond: Catch a wave}

Med kunstens kontekstualisering er receptionskategorier blevet produktionskategorier, og betragtere er blevet producenter. En påstand: hvis det er rigtigt, sådan som Miwon Kwon har formuleret det, at I970ernes kunstretning institutionskritikken prøvede at være et verbum/proces $\mathrm{i}$ stedet for den konventionelle kunstpraksis' navneord/objekt, befinder vi os måske nu i adjektivets/medieringens tid.5 Navneordene er (altid allerede) etablerede. Processerne kører. Og vi modulerer og gradbøjer med post-media-praksis.

Som allerede nævnt berører post-media-praksis autorens konstitution; man kan tale om en 'soft author'. Idet kunstproduktion handler om udvælgelse og organisering af objekter i rum, er kuratoren udstillingsarrangøren - således forstået også en slags kunstner. Omvendt er kunstneren i post-medialitetens åbne og pulserende terræn blevet til en mellemmand/kvinde, $\mathrm{i}$ stand til at mediere sig selv og andre som konsument-producenter. En sådan "mellemmands-subjektivitet" er symptomatisk for en postmedial tid, med dens formidlere, producere, spindoktorer, DJs, facilitatorer, trendlæsere etc.; i særdeleshed, hvis man angiver post-media-praksissens grundvilkår som det, Guy Debord kaldte for den bureaukratiske kapitalisme. ${ }^{6}$

Kunstneren Joseph Kosuth hævdede i I970, at konceptkunsten havde annekteret mellemmanden, idet den ved at være sprogligt konstitueret havde integreret kunstkritikkens funktion i sig; der var nu direkte forbindelse mellem kunst og betragter. Gilles Deleuze havde bedre brug for mellemmanden, eller mediatoren, som han foretrak at kalde figuren. I et interview af samme titel fra 1985 opsummerer han idéproduktion som en intervention i, eller forbinden sig med, hvad der allerede er der: en sætten i kredsløb. 7 Hvad der er vigtigt for Deleuze, er ikke at være en oprindelse for en indsats, men i stedet hvordan man bliver del af noget. I en inspirerende formulering taler Deleuze om at blive "fejet med af en stor bølge eller en søjle af opadgående luft.” Han opfordrer moderne tænkere til at holde op med at være kustoder, og i stedet meditere over oprindelser og evige værdier. Bevægelse er skabelse. Man hægter sig på en bevægelse og ser, hvad den kolliderer med. Det er en strategi, hvor man engagerer sig i tættere forbindelser med folk og discipliner for at spørge til ekkoer og genklange imellem dem. Deleuze skriver:

Mediatorer er fundamentale. Skabelse handler helt og holdent om mediatorer. Uden dem sker der ingenting. De kan være 
folk - for en filosof, kunstnere eller videnskabsfolk; for en videnskabskvinde, filosoffer eller kunstnere - men også ting, selv planter eller dyr, som hos Carlos Castaneda. Hvad enten de er virkelige eller imaginære, levende eller døde, må man forme sine mediatorer. Det er serier. Hvis ikke man befinder sig i en serie, selv en helt imaginær serie, så er man fortabt. Jeg har brug for mine mediatorer til at udtrykke mig, og de ville aldrig udtrykke sig uden mig: du er altid i en gruppe, selv når du tilsyneladende er alene. ${ }^{8}$

Deleuzes mediator går imod institutionaliseret sandhed. Der er ingen sandhed, som ikke "forfalsker" etablerede idéer $\mathrm{i}$ intense forhandlinger og produktiv uorden. En sandhed er produceret, den bliver fabuleret og improviseret frem i gruppens synergi. Eller som Slater beskriver den post-mediale mangfoldighed:

Alle scener er deres egen genre, og ved at fungere i spredte geografiske og psykiske rum er der ingen følelse af, at nogen som helst enkeltperson, -gruppe eller -scene dominerer: det er en additionens praksis uden akkumulation (...).

De egenskaber eller miljøer, som mediatorer gør nærværende $\mathrm{i}$ en given proces - begreber, funktioner, stile, sanseapparater etc. - er klausuler på sandheden.

\section{Martyrer og service-industrier}

Deleuze repræsenterer en position, man kunne kalde for typisk I98oerne, i den forstand, at han argumenterer for en blanding af diskurser, et cross-over. $\mathrm{Og}$ dog føles det, som om han ser lige igennem krystalkuglen til vor tid. Han konkluderer, at "repressive kræfter forhindrer ikke folk $\mathrm{i}$ at udtrykke sig, men tvinger dem snarere til at udtrykke sig." Robotten Rosa er en vulgariseret udgave af Deleuzes behov for at have en mediator til at hjælpe med at udtrykke sig. I forlængelse heraf står IT-samfundets utopi, med Bill Gates' forhåbning om tilsynekomsten af en ideel, friktionsfri kapitalisme: "The information highway will extend the electronic marketplace and make it the ultimate go-between, the universal middleman."9

Med andre ord, bevægelsen er blevet noget foreskrevet. Post-medialitetens mangfoldighed, overskri- delser og transformationer - i sin bureaukratisk-kapitalistiske opsætning - er blevet normativ. Hvad er der er sket? I stedet for Deleuzes faglige forum af forskellige discipliner har en anden player set dagens lys. Den cubansk-amerikanske kunstner Jorge Pardo arbejder i et tidstypisk krydsfelt mellem kunst, design og arkitektur. Han er en selverklæret mellemmand: "Der er en masse stuff derude som er mere interessant end mit arbejde, men mit arbejde er en model for at kigge på stuff." Han har beskrevet sin kunstneriske praksis som bragesnak eller en tagen pis på (bullshitting). Hans talent består i at destabilisere ting, han kan få dem til at gå galt til en vis grad, hvorved de bliver "poetiske"; heri består forbindelsen fra Deleuzes falsificerende mediatorer til nutidskunstens afsværgelse af klare produktive identiteter.

Hvad der hos Pardo forhindrer kunstens ræson i at fordampe i hans praksis' interdisciplinaritet, er hans gravitet som autor. Den fysiske produktion af hans værker kræver ikke nødvendigvis hans fysiske indblanding; signaturen Jorge Pardo er en form for mester-workshop, som er kalibreret til kunstsystemets standarder for management. Pardos egen organisation er på den måde en vigtig, men usynlig undertekst for Pardos kunst. Og hvad er der så i vejen med det? Hvorfor problematisere appropriation og out-sourced kunstnerisk produktion, ofte benyttede post-media-strategier i nutidskunsten?

Problemet er selvfølgelig ikke, at ikke-kunstnerisk "stuff" approprieres af Pardo, men, i stedet, at han og mange andre hævder at arbejde i kapitalismens mellemrum. Ifølge Nicolas Bourriaud - som formulerede den indflydelsesrige relationelle æstetik i I995, arbejder en kunstner som Pardo med at oprette nye sociale rum for at imødegå konsumsamfundets passivitet; eller han arbejder i gavens område, snarere end $\mathrm{i}$ varens. At tale om gavmildhed eller social utopi er en dissimulering af kunstsystemets præmisser i de institutionelle og kommercielle markeder, som appellerer til post-mediale instanser som kollektivt forfatterskab, uafgrænset disciplinaritet og selvdefinerende produktive handlinger. Pardos definition af sig selv som en bullshitter tager sig derfor ud som en falsk falsifikation, idet den i grun- 
den er en verifikation af kunstsystemets eksisterende infrastruktur. Jo mere han bullshitter, jo mere funktionel er han. Det er bullshitting som serviceydelse.

Lad os overveje et andet post-media eksempel, der på en anden måde handler om at navigere i gråzoner, som er omstridt af forskellige definitioner.Ved den libanesiske borgerkrigs begyndelse i slutningen af I970erne blev kunstneren Tony Shakars far - en politimand - skudt og dræbt. Som enke til en tjenestemand var Shakars mor berettiget til en pension. Det viste sig, at hvis hun indberettede, at hendes mand døde som martyr, ville hun kunne få en højere pensionsrate. Så på grund af disse overlapninger mellem bureaukrati og religion led Shakars far martyrdøden. Situationens kompleksitet bestod i, at martyrium er en muslimsk tradition, og Shakars familie er kristne. Oven i dette var der selvfølgelig den omstændighed, at den afdøde mands identitet syntes at forsvinde $\mathrm{i}$ den universaliserende, religiøse diskurs, som omgiver et martyrium. Shakar besluttede sig dog for at lade sig drive med af denne redefinition af sin far.Via mellemmænd bestilte han et martyrportræt af den afdøde fra en af Hizbollah-militsens officielle martyr-portrætmalere. I Beirut holder Hizbollah et par håndværksmalere beskæftigede med at eksekvere portrætter og udendørs vægmalerier af dem, som døde i Kampen. Martyrportrætter er en ret standardiseret affære; man indleverer et foto af den afdøde og får ham eller hende tilbage i en idealiseret udgave i uniform eller religiøs klædning, på baggrund af en nattehimmel og en oase med palmetræer.

Men da Shakar fik sin fars færdige martyrportræt udleveret, var der sket noget sært - cedertræer. I Libanon gror cedertræer i det kølige klima i bjergene og er således uforenelige med ørkenens palmer. Hizbollah-maleren havde tydeligvis fundet ud af, at den afdøde politimand, han havde fået besked på at male, ikke var muslim, og cedertræerne var hans måde at kommentere den ideologiske konflikt, idet cedertræerne er symboler for det kristne Libanon. På denne måde adopterede både Hizbollah-kunstnere og Shakar borgerkrigens repræsentationspolitiske tvetydigheder.

Shakar blev selvfølgelig godt hjulpet af, at hans fatalitet blev gengældt af Hizbollah-malerens sympatiske indstilling. Så hvordan kan man navigere $\mathrm{i}$ dette de-territorialiserede terræn? Vi må tilbage til spørgsmålet om, hvor organiseringen af det postmediale rum finder sted.

\section{Materielt liv}

I historikeren Fernand Braudels bog fra 1977, Afterthoughts on Material Civilization and Capitalism, beskrives folk som underlagt historien, ikke som historiens aktører. I historiens kontinuum er folk således strukket ud mellem hverdagsrutiner på den ene side og indiskutable kræfter som krige, politik og demografiske bevægelser på den anden.

På denne måde ser Braudel historien som en række af længerevarende ligevægts- eller uligevægtstilstande. Braudels værk er en klart skrevet, kort afhandling om den økonomiske histories marginer, nedre grænser og accelerations- og stagnationsfaser.

Braudel foretager en trisektion mellem materielt liv, markedsøkonomi og kapitalisme. Det materielle liv defineres her som hverdagslivet $i$ alle dets rutiner og vaner. Braudel viser, hvordan kapitalismen indtil det I8. århundrede kun berørte en minoritet; størstedelen af den vestlige og koloniserede verdens befolkninger var involverede i selv-tilstrækkelige økonomier. Markedsøkonomien lænker produktion og konsumption, og dens mekanismer er forholdsvis transparente, blandt andet fordi den ofte var konstitueret af direkte udvekslinger.

Kapitalismen er

a congeries of easily identifiable financial resources, constantly at work; a capitalist is a person who presides or attempts to preside over the insertion of capital into the ceaseless process of production to which every society is destined; and capitalism is roughly (but only roughly) speaking the manner in which this constant activity of insertion is carried on, generally for not very altruistic reasons. ${ }^{\mathrm{IO}}$

Kapitalismen kan kun vokse og tage form i det omfang, det er den tilladt af dens underliggende økonomier, dobbeltlaget af markedsøkonomi og hverdagsliv. Med andre ord benytter kapitalismen sig af eksisterende hierarkier, markeder og forbrugsmøns- 
tre. Braudel sætter det på formel ved at sige, at kapitalismen altid kommer for sent: den ankommer, når alt er parat. Den akkumulerer på materielt liv og lægger sig imellem marked og hverdagsliv.

Lad os tage et eksempel. Sidste år åbnede Centre for Contemporary Art i Glasgow en bar, hvis interiør og elementer var designet af Jorge Pardo. Som kunstprojekt samler baren materielt liv (den almindelige bar-socialisering); markedsøkonomi (køb og salg over bardisken); og en kapitalistisk dimension (i kunstsystemets perspektiv indsættelsen af baren som akkumulationsaggregat $\mathrm{i}$ det materielle liv). Hvis man på denne måde italesætter Pardos produktion som "poesi”, "mellemrum i kapitalismen" eller "nyt socialt rum", artikuleres således en indistinkt signifikation af de tre erfarings- og økonomiske dimensioner, som er aktive i CCA-baren. Vi er alle involverede $\mathrm{i}$ oversættelser eller vekslinger mellem materielt liv, markedsøkonomi og kapitalisme, og agerer i deres kombinerede sfære. Post-mediale praksisser kræver et synkront, empatisk blik, som kan artikulere simultaniteten af aktiviteter og deres materielle betingelser, i deres uafhængighed af grænser og discipliner.

\section{Noter}

I. Denne "organ-metaforiske" problemstilling formulerer Georg Christoph Tholen således, med henvisning til Kittler: "Der spiegelbildliche Doppelgänger dieser ganzheitlichen Organ-Metaphorik, welche den Menschen als Quasi-Maschine definiert, ist die universalisierung der Maschine als Nicht-Mensch, die den Menschen - zumindest tendenziell - ersetzt. Auch eine solche Mediendefinition, für die exemplarisch Friedrich Kittlers Diskursanalyse der technischen Codes als Träger von Medien stehen mag, kommt (...) nicht umhin, die Metaphorik der Imitation und Implementierung, des Simulierens und Ersetzens (etwa von Subjektivität und Intelligenz) zu verwenden." Georg Christoph Tholen: Die Zäsur der Medien, Kulturphilosophische Konturen, Suhrkamp Taschenbuch Wissenschaft, Frankfurt am Main, 2002, s. 29.

2. Det postmoderne indebærer dog ikke nødvendigvis en post-media-position. For eksempel argumenterer de Man i sin introduktion til The Resistance to Theory, at ligesom vi (i de Mans emfatiske forstand) laser bogen, skal vi 'læse malerier'. Her bliver læsningens modalitet disciplinerende som en specialiseret vedligeholdelse af det uspaltede mediums overordnede register. The Resistance to Theory, Uni- versity of Minnesota Press, Minneapolis 1997.

3. Felix Guattari: Guattari reader, red. G. Gesonko, Blackwell, I996, s. I36. I forhold til musikscenerne kan man argumentere for, at post-media er, hvad man tidligere kaldte for "undergrund" - dog med den forskel, at selv undergrunden ofte havde politiske overbygninger af frigørende art. For så vidt er post-media-scenen mere selv-refererende, en til en.

4. Boris Groys, interview af Lars Bang Larsen: Lettre Internationale, efterår 2003 s. 64. Post-medialitetens forhold til arkivet er således et åbent spørgsmål, som Groys har beskæftiget sig indgående med. Bl.a. konfronterer han den kritiske teoris arkivskepsis således, hvilket det også kunne være interessant at udfolde $\mathrm{i}$ forhold til det post-mediales tidsopfattelse: "Die kritische Theorie von Heute argumentiert nicht mit dem Zeitüberfluss, sondern mit der Zeitknappheit - und damit in Namen des unstabilen, Fliessenden, Sich-dem-Zugriff-Entziehenden, Nicht-kontrollierbaren. Die Zeit wird dabei als endliches Ereignis interpretiert, das jede Planung, jede ökonomische Rationalität, jedes Marktkalkül gefährdet. (...) Für die Archive erweist sich ein solches Zeitverständnis offentsichtlich als besonderes ungünstig."

5. Miwon Kwon: One Place After Another: Notes on Site Specificity, MIT Press, Cambridge, I997, s. 102

6. Guy Debord: Commentaires sur la société du spectacle, Gallimard, Paris, I992.

7. Gilles Deleuze: "Mediators", in Incorporations, red. Jonathan Crary \& Sanford Kwinter, Zone Books, I994, New York.

8. Ibid., s. 125 .

9. Toni Negri \& Michael Hardt: Empire, Harvard University Press, Cambridge, Mass, 2000, s. 296.

Io. Fernand Braudel: Afterthoughts on Material Civilization and Capitalism, The Johns Hopkins University Press, Baltimore, 1977, s. 52.

\section{Litteratur}

Braudel, Fernand: Afterthoughts on Material Civilization and Capitalism, The Johns Hopkins University Press, Baltimore, 1977

Debord, Guy: Commentaires sur la société du spectacle, Gallimard, Paris, I992.

Deleuze, Gilles: "Mediators", in Incorporations, red. Jonathan Crary \& Sanford Kwinter, Zone Books, New York I994

Guattari, Felix: Guattari reader, red. G. Gesonko, Blackwell, 1996

Groys Boris, interview af Lars Bang Larsen: Lettre Internationale, efterår 2003

Kwon, Miwon: One Place After Another: Notes on Site Specificity, MIT Press, Cambridge 1997 
de Man, Paul: The Resistance to Theory, University of Minnesota Press, Minneapolis, 1997

Negri, Toni \& Michael Hardt: Empire, Harvard University

Press, Cambridge, Mass., 2000

Tholen, Georg Christoph: Die Zäsur der Medien, Kultur- philosophische Konturen, Suhrkamp Taschenbuch Wissenschaft, Frankfurt am Main, 2002. 
